Review began 08/18/2021 Review ended 08/30/2021 Published 09/07/2021

(c) Copyright 2021

Mahmoud et al. This is an open access article distributed under the terms of the Creative Commons Attribution License CCBY 4.0., which permits unrestricted use distribution, and reproduction in any medium, provided the original author and source are credited.

\section{Study of Post-COVID-19 Syndrome in Saudi Arabia}

Manal H. Mahmoud ${ }^{1,2}$, Fahad A. Alghamdi ${ }^{3}$, Ghaida A. Alghamdi ${ }^{3}$, Loai A. Alkhotani ${ }^{3}$, Mohammad A. Alrehaili $^{3}$, Dalia K. El-Deeb ${ }^{2}$

1. Community Medicine, Ibn Sina National College for Medical Studies, Jeddah, SAU 2. Community Medicine, Alexandria Faculty of Medicine, Alexandria, EGY 3. Medicine, Ibn Sina National College for Medical Studies, Jeddah, SAU

Corresponding author: Manal H. Mahmoud, manal.azab@gmail.com

\section{Abstract \\ Background}

Post-COVID-19 syndrome may be predisposed by organ damage as a complication of COVID-19. Patients may experience persistent symptoms after recovering from their initial illness.

\section{Objectives}

To identify manifestations and predisposing factors for post-COVID-19 syndrome in Saudi Arabia.

\section{Methods}

A cross-sectional study was conducted from May 2021 through June 2021 using an online structured precoded closed-ended, pilot-tested questionnaire in Arabic. It included male and female inhabitants of Saudi Arabia aged 18 years and above with a past history of COVID-19 infection. Descriptive statistics were carried out for all variables. A univariate analysis Chi-square test and independent t-test were used. A p-value of less than 0.05 was considered significant.

\section{Results}

A total of $85.3 \%$ of post-COVID-19 cases had general manifestations: $77.3 \%$ had musculoskeletal and joint complaints, $61.3 \%$ had mental and psychological problems, 58.7\% had gastrointestinal manifestations, $44 \%$ had renal complaints, $41.3 \%$ had respiratory complaints, and $36.0 \%$ had cardiovascular symptoms. Gender, age, smoking, BMI, associated morbid condition, number of previous COVID-19 attacks, the severity of illness, place of treatment, and complications of COVID-19 due to treatment or hospitalization were significantly correlated with the occurrence of post-COVID-19 syndrome.

\section{Conclusion}

Post-COVID-19 syndrome could be manifested by fatigue, malaise, myalgia, joint pain, depression, anxiety, sleep, memory and concentration disturbances, cough, dyspnea, palpations, arrhythmias, and chest pain. It may be influenced by male gender, smoking, old age, high BMI, comorbidities, and past COVID-19 attacks with regard to the number, place of treatment, and occurrence of complications.

Categories: Infectious Disease, Public Health

Keywords: saudi arabia, covid-19, post covid-19 syndrome, pandemic, predisposing factors

\section{Introduction}

COVID-19 is a zoonotic respiratory disease that started in Wuhan city in China and turned into a pandemic stated by World Health Organization (WHO) [1].

COVID 19 is manifested by cough, fever, shortness of breath, sudden onset of an abnormal smell (anosmia or cacosmia), loss, or impaired taste (ageusia or dysgeusia). Other manifestations include confusion, chills, fatigue, generalized myalgia, malaise, drowsiness, cough, acute respiratory distress syndrome with dyspnea and pneumonia, a severe gastrointestinal disorder with diarrhea, liver injury, coagulation dysfunction, cardiovascular failure, and other clinically relevant neurological involvement. It is confirmed by the detection of SARS-CoV-2 nucleic acid or antigen in a clinical specimen [2-4].

Although WHO planned recommendations to control the COVID-19 pandemic, waves of the pandemic are still present [5]. It has a mortality rate of 5-6\%, with about 3.6 million worldwide deaths. It affected nearly 172 million people worldwide; $75 \%$ of them recovered either completely or with some complications. Arab countries of the Gulf, including the Kingdom of Saudi Arabia, are the least affected [6]. 
People who are in close contact with infected persons and those with impaired immunity and chronic medical conditions are more susceptible to the disease and its complications [1]. Mortality is higher among males in all age groups [7]. Complications of COVID-19 include acute respiratory failure, pneumonia, acute respiratory distress syndrome, acute liver injury, acute cardiac injury, secondary infection, acute kidney injury, septic shock as well as post-COVID-19 syndrome and death [8].

The post-COVID-19 syndrome is a syndrome of persistent symptoms or development of sequelae beyond 3 or 4 weeks from the onset of acute symptoms of COVID 19 attack regardless of the severity of this attack. It could be also defined as persistent symptoms and/or delayed or long-term complications of SARS-CoV-2 infection beyond 4 weeks from the onset of symptoms [9 -13]. Based on recent literature, it could be divided into two types: (1) subacute or ongoing symptomatic COVID-19, which includes symptoms and abnormalities present from 4-12 weeks beyond acute COVID-19; and (2) chronic or post-COVID-19 syndrome, which includes symptoms and abnormalities persisting or present beyond 12 weeks of the onset of acute COVID-19 and not attributable to alternative diagnoses [12]. The main presentations are fatigue, shortness of breath or difficulty breathing, cough, joint, muscle, and chest pain, memory disturbances, concentration or sleep problems, headache, tachycardia, loss of smell or taste, depression or anxiety, fever, dizziness [9].

Post-COVID-19 syndrome may result in organ damage that resulted as sequelae of COVID-19, multisystem inflammatory syndrome following COVID 19 illness, blood clots, and leaking blood vessels that complicate COVID-19 may be another predisposing factor [9].

Little is known about the manifestations and predisposing factors for post-COVID-19 syndrome throughout the world and in Saudi Arabia. So this study was carried out to answer the following questions: What are the manifestations and predisposing factors of the post-COVID-19 syndrome in Saudi Arabia?

\section{Materials And Methods \\ Study context and design}

A cross-sectional study using an online questionnaire conducted by researchers from Ibn Sina National College for Medical Studies (ISNC) starting from May 2021 through June 2021.

\section{Sampling}

A voluntary response convenient sample of male and female participants aged above 18 years old with a past history of COVID-19 infection were included. The sample size was arrived at using the margin of error approach as seen in the equation below:

$\mathrm{n}=\mathrm{Z} 2 \mathrm{P}(1-\mathrm{P}) / \mathrm{d} 2$

where $\mathrm{n}$ is the sample size, $\mathrm{Z}$ is the statistic corresponding to the level of confidence, $\mathrm{P}$ is expected prevalence (that can be obtained from the same studies or a pilot study conducted by the researchers), and d is precision (corresponding to effect size) [14].

The sample size was set at 150 participants divided into two groups according to whether they suffered from the post-COVID-19 syndrome or not.

$\mathrm{n}=\mathrm{Z} 2 \mathrm{pq} / \mathrm{d} 2$

Where,

$\mathrm{Z} 2=\mathrm{Z}$ raised to power 2

$\mathrm{d} 2=\mathrm{d}$ raised to power 2

$\mathrm{n}=$ minimum sample size

$\mathrm{Z} 2$ = Standard score corresponding to a given confidence level. Example, at $95 \%$ confidence level or $5 \%$ level of significance $(\mathrm{a}=0.05), \mathrm{Z}=1.96$.

$\mathrm{P}=$ Prevalence of disease is $1 \%$

$q=(1-p)$ or percentage of failure which is $100-1=99 \%$

$\mathrm{d}=$ Precision limit or proportion of sampling error, which is usually $5 \%$ confidence limit. 


\section{Cureus}

$\mathrm{n}=\mathrm{Z} 2 \mathrm{P}(1-\mathrm{q}) / \mathrm{d} 2$

The actual prevalence of COVID-19 in the Kingdom of Saudi Arabia was nearly 1.7 (about 600,000 cases with a total population of 35 million).

Here, in the equation, the prevalence used was .01 (as expected among the studied group, for response rate and duration and feasibility of the study)

\section{Data collection methods}

A structured pre-coded closed-ended, pilot-tested questionnaire in Arabic was developed. It included the following data: demographic data (age, sex, marital status, education, occupation, smoking history, and BMI), medical history, COVID-19 vaccination state, history of last COVID-19 attack, and clinical manifestation of post-COVID-19. The reliability of the questionnaire (content validity) was tested by SPSS Statistics (IBM Corp, Armonk, USA) using Cronbach's alpha test $(r=0.89)$.

\section{Statistical analysis}

Data were collected and processed using SPSS version 22. Descriptive statistics were carried out for all variables. The participants were divided into two groups: Group I without post-COVID-19 syndrome and Group II with post-COVID-19 syndrome (according to the following: persistent symptoms of COVID-19 or development of sequelae beyond 4 weeks from the onset of acute symptoms of COVID-19 attack). A univariate analysis Chi-square test and independent t-test were used. A p-value $<0.05$ was considered statistically significant. Spearman's correlation was used to study the predisposing factors for developing the post-COVID-19 syndrome.

\section{Ethical considerations}

Ethical approval for the study was obtained from Ibn Sina National College (ISNC) Research and Ethics Committee (IEC Ref No: H-04-03062021) in accordance with the Declaration of Helsinki for Human Studies [14]. Participation in the study was voluntary and during the online questionnaire, the participants were all informed about the purpose of the study and their right to refuse participation. Ethical conduct was maintained during data collection and throughout the research process.

\section{Results}

The total number of participants that were included in the study was 150 , divided into two groups. The first group was without post-COVID-19 syndrome and the second group suffered from post-COVID- 19 syndrome.

More than half (57.3\%) of the participants were females, $54.7 \%$ were not married. The mean age of the study participants was $32.8(5.52)$ years $(\mathrm{p}=0.042)$. Only $24.7 \%$ were nonsmokers, the remaining were either passive smokers $(13.3 \%)$, cigarette smokers $(44.7 \%)$, shisha smokers $(10.0 \%)$, or vape smokers $(7.3 \%)(p=0.039)$. The mean BMI was 25.9 (3.21) $(\mathrm{p}=0.041)$ (Table 1$)$. 


\section{Cureus}

\begin{tabular}{|c|c|c|c|c|c|c|}
\hline & & & Group I N=75 (\%) & Group II N=75 (\%) & Total $\mathrm{N}=150(\%)$ & p-value \\
\hline \multirow{2}{*}{ Gender } & \multicolumn{2}{|l|}{ Male } & $33(44)$ & $31(41.3)$ & $64(42.7)$ & \multirow{2}{*}{$0.041^{*}$} \\
\hline & \multicolumn{2}{|l|}{ Female } & $42(56)$ & $44(58.7)$ & $86(57.3)$ & \\
\hline \multicolumn{3}{|l|}{ Age in years Mean (Sd) } & $29.3(6.91)$ & $36.2(7.65)$ & $32.8(5.52)$ & $0.042^{*}$ \\
\hline \multirow{2}{*}{ Nationality } & \multicolumn{2}{|l|}{ Non Saudi } & $12(16.0)$ & $14(18.7)$ & $26(17.3)$ & \multirow{2}{*}{0.501} \\
\hline & \multicolumn{2}{|l|}{ Saudi } & $63(84.0)$ & $61(81.3)$ & $124(82.7)$ & \\
\hline \multirow{2}{*}{ Place of residence } & \multicolumn{2}{|c|}{ Mekka Region } & $48(64.0)$ & $43(57.3)$ & $91(60.7)$ & \multirow{2}{*}{0.590} \\
\hline & \multicolumn{2}{|c|}{ Outside Mekka Region } & $27(36.0)$ & $32(42.7)$ & $59(39.3)$ & \\
\hline \multirow{2}{*}{ Marital status } & \multicolumn{2}{|l|}{ Never married } & $43(57.3)$ & $39(52.0)$ & $82(54.7)$ & \multirow{2}{*}{0.679} \\
\hline & \multicolumn{2}{|l|}{ Ever married } & $32(427)$ & $36(48.00)$ & $68(45.3)$ & \\
\hline \multirow{3}{*}{ Education } & \multicolumn{2}{|l|}{ Basic education } & $6(8.0)$ & $8(10.7)$ & $14(9.3)$ & \multirow{3}{*}{0.725} \\
\hline & \multicolumn{2}{|c|}{ Secondary school } & $20(26.7)$ & $16(21.3)$ & $36(24.0)$ & \\
\hline & University and $\mathrm{i}$ & & $49(65.3)$ & $51(68.0)$ & $100(66.7)$ & \\
\hline \multirow{3}{*}{ Work status } & Not working & & $32(42.7)$ & $27(36.0)$ & $59(39.3)$ & \multirow{3}{*}{0.810} \\
\hline & Private sector & & $13(17.3)$ & $11(14.7)$ & $24(16.0)$ & \\
\hline & Governmental s & & $30(40.0)$ & $37(49.3)$ & $67(44.7)$ & \\
\hline \multirow{5}{*}{ Smoking history } & Non smoker & & $23(30.7)$ & $14(18.7)$ & $37(24.7)$ & \multirow{5}{*}{$0.039^{*}$} \\
\hline & Passive smoke & & $12(16.0)$ & $8(10.7)$ & $20(13.3)$ & \\
\hline & \multirow{3}{*}{ Active Smoker } & Cigarette & $29(38.7)$ & $38(50.7)$ & $67(44.7)$ & \\
\hline & & Shisha & $10(13.3)$ & $5(6.7)$ & $15(10.0)$ & \\
\hline & & Vape & $6(8.0)$ & $5(6.7)$ & $11(7.3)$ & \\
\hline \multicolumn{3}{|l|}{ BMI Mean (Sd) } & $22.4(5.66)$ & $29.6(4.78)$ & $25.9(3.21)$ & $0.041^{x}$ \\
\hline
\end{tabular}

\section{TABLE 1: Socio-demographic characters of the study participants}

${ }^{*} \mathrm{P}$-value is significant at less than 0.05 level

Group I N=75 ( without post-COVID-19 syndrome)

Group II N=75 ( with post-COVID-19 syndrome)

Group II significantly had $45.3 \%$ with cardiovascular diseases, 57.3\% with respiratory diseases, and $27.3 \%$ with hepatic diseases $(\mathrm{p}=0.042,0.032,0.046$ respectively). Nearly half of the participants $(48.0 \%)$ were partially vaccinated (received one dose) and $29.3 \%$ were fully vaccinated (Table 2 ). 


\section{Cureus}

\begin{tabular}{|c|c|c|c|c|c|c|}
\hline & & & Group I N=75 (\%) & Group II N=75 (\%) & Total $\mathrm{N}=150(\%)$ & p-value \\
\hline \multirow{2}{*}{ Cardiovascular } & \multicolumn{2}{|l|}{ No } & 62 (82.7) & 41(54.7) & $103(68.7)$ & \multirow{2}{*}{$0.042^{*}$} \\
\hline & Yes & & 13 (17.3) & 34 (45.3) & 47 (31.3) & \\
\hline \multirow{2}{*}{ Respiratory } & No & & 47 (62.7) & $32(42.7)$ & 79 (52.7) & \multirow{2}{*}{$0.032^{*}$} \\
\hline & Yes & & $28(37.3)$ & $43(57.3)$ & $71(47.3)$ & \\
\hline \multirow{2}{*}{ Endocrine } & No & & $66(88.0)$ & $54(72.0)$ & $120(80.0)$ & \multirow{2}{*}{0.610} \\
\hline & Yes & & $9(12.0)$ & $21(28.0)$ & $30(20.0)$ & \\
\hline \multirow{2}{*}{ Liver } & No & & $63(84.0)$ & 46 (61.3) & 109 (72.7) & \multirow{2}{*}{$0.046^{*}$} \\
\hline & Yes & & $12(16.0)$ & $29(38.7)$ & 41(27.3) & \\
\hline \multirow{2}{*}{ Renal } & No & & 51(68.0) & $48(64.0)$ & $99(66.0)$ & \multirow{2}{*}{0.052} \\
\hline & Yes & & 24(32.0) & $27(36.0)$ & $51(34.0)$ & \\
\hline \multirow{3}{*}{ Vaccination } & No & & 13(17.3) & $21(28.0)$ & 34 (22.7) & \multirow{3}{*}{0.134} \\
\hline & \multirow{2}{*}{ Yes } & Partial & $39(52.0)$ & $33(44.0)$ & $72(48.0)$ & \\
\hline & & Full & $23(30.7)$ & 21(28.0) & 44 (29.3) & \\
\hline
\end{tabular}

\section{TABLE 2: Associated morbid conditions of the study participants}

${ }^{*} \mathrm{P}$-value is significant at less than 0.05 level

Group I N=75 ( without post-COVID-19 syndrome)

Group II N=75 ( with post-COVID-19 syndrome)

Table 3 illustrates that dyspnea, fever, cacosmia, loss of taste and headache were the dominant symptoms of the COVID- 19 attack of the studied participants $(85.3 \%, 82.7 \%, 82.7 \%, 67.3 \%, 57.3 \%$, respectively; $p=0.033$, $0.142,0.029,0.036$ and 0.061 , respectively). Nearly half (48.7\%) of past COVID-19 cases were treated at home $(\mathrm{p}=0.046), 50.7 \%$ were mild cases $(\mathrm{p}=0.039)$, and $60.7 \%$ completely cured immediately after infection $(\mathrm{p}=0.035)$. Complications that occurred due to treatment or hospitalization for last COVID-19 attack included fatigue $(63.3 \%$; $\mathrm{p}=0.029)$, post-traumatic stress disorder $(54.0 \%$; $\mathrm{p}=0.461)$, and malaise $(39.3 \%$; $\mathrm{p}=0.032$ ) (Table 3).

\begin{tabular}{|c|c|c|c|c|c|}
\hline & & Group $1 \mathrm{~N}=75$ (\%) & Group II N=75 (\%) & Total $\mathrm{N}=150(\%)$ & p-value \\
\hline \multicolumn{2}{|l|}{ Number of attacks: Mean (Sd) } & $1.3(1.26)$ & $1.9(1.45)$ & $1.7(0.95)$ & 0.065 \\
\hline \multicolumn{6}{|l|}{ Symptoms present when infected } \\
\hline \multirow{2}{*}{ Fever } & No & $15(20.0)$ & $11(14.7)$ & $26(17.3)$ & \multirow{2}{*}{0.142} \\
\hline & Yes & $60(80.0)$ & $64(85.3)$ & $124(82.7)$ & \\
\hline \multirow{2}{*}{ Dyspnea } & No & $13(17.3)$ & $9(12.0)$ & $22(14.7)$ & \multirow{2}{*}{$0.033^{*}$} \\
\hline & Yes & $62(82.7)$ & $66(88.0)$ & $128(85.3)$ & \\
\hline \multirow{2}{*}{ Cacosmia } & No & $18(24.0)$ & $8(10.7)$ & $26(17.3)$ & \multirow{2}{*}{$0.029^{*}$} \\
\hline & Yes & $57(76.0)$ & 67(89.3) & $124(82.7)$ & \\
\hline \multirow{2}{*}{ Loss of taste } & No & $26(34.7)$ & $23(30.7)$ & $49(32.7)$ & \multirow{2}{*}{$0.036^{*}$} \\
\hline & Yes & $49(65.3)$ & $54(69.3)$ & $101(67.3)$ & \\
\hline \multirow{2}{*}{ Headache } & No & $33(44.0)$ & $31(41.3)$ & $64(42.7)$ & \multirow{2}{*}{0.061} \\
\hline & Yes & $42(56.0)$ & $44(58.7)$ & $86(57.3)$ & \\
\hline
\end{tabular}




\section{Cureus}

\begin{tabular}{|c|c|c|c|c|c|}
\hline \multirow[t]{2}{*}{ Diarrhea } & No & $38(50.7)$ & $36(48.0)$ & $74(49.3)$ & \multirow[t]{2}{*}{0.561} \\
\hline & Yes & 37 (49.3) & $39(52.0)$ & $76(50.7)$ & \\
\hline \multirow{2}{*}{ Constipation } & No & $45(60.0)$ & $47(62.7)$ & $92(61.3)$ & \multirow{2}{*}{0.438} \\
\hline & Yes & $30(40.0)$ & $28(37.3)$ & $58(38.7)$ & \\
\hline \multicolumn{6}{|l|}{ Place of treatment } \\
\hline Home & & 43 (53.3) & $30(40.0)$ & 73(48.7) & \multirow{3}{*}{$0.046^{*}$} \\
\hline Hospital & & $20(26.7)$ & $16(21.3)$ & $36(24.0)$ & \\
\hline ICU & & $12(16.0)$ & $29(38.7)$ & $41(27.3)$ & \\
\hline \multicolumn{6}{|l|}{ Severity of illness } \\
\hline Mild & & $41(54.7)$ & $35(46.7)$ & $76(50.7)$ & \multirow{3}{*}{$0.039^{*}$} \\
\hline Moderate & & $23(30.7)$ & $31(41.3)$ & $54(36.0)$ & \\
\hline Sever & & $11(14.6)$ & $9(12.0)$ & $20(13.3)$ & \\
\hline \multirow{2}{*}{ Complete cure after infection } & No & $14(18.7)$ & $45(60.0)$ & $59(39.3)$ & \multirow{2}{*}{$0.035^{*}$} \\
\hline & res & $01(01.0)$ & $30(40.0)$ & $91(60.1)$ & \\
\hline \multicolumn{6}{|c|}{ COVID-19 Complications due to treatment or hospital admission } \\
\hline \multirow{2}{*}{ Malaise } & No & $52(69.3)$ & $39(52.0)$ & $91(60.7)$ & \multirow{2}{*}{$0.032^{*}$} \\
\hline & Yes & $23(30.7)$ & $36(48.0)$ & $59(39.3)$ & \\
\hline \multirow{2}{*}{ Fatigue } & No & $34(45.3)$ & $21(28.0)$ & $55(36.7)$ & \multirow{2}{*}{$0.029^{*}$} \\
\hline & Yes & 41(54.7) & $56(72.0)$ & $95(63.3)$ & \\
\hline \multirow{2}{*}{ Post-traumatic stress disorder } & No & $33(44.0)$ & $36(48.0)$ & $69(46.0)$ & \multirow{2}{*}{0.461} \\
\hline & Yes & $42(56.0)$ & $39(52.0)$ & $81(54.0)$ & \\
\hline \multirow{2}{*}{ Post-intensive care syndrome } & No & 61(81.3) & $52(69.3)$ & $113(75.3)$ & \multirow{2}{*}{$0.049^{*}$} \\
\hline & Yes & 14 (18.7) & $23(30.7)$ & $37(24.7)$ & \\
\hline
\end{tabular}

\section{TABLE 3: Description of previous COVID-19 attack of the studied participants}

${ }^{*} \mathrm{P}$-value is significant at less than 0.05 level

Group I N=75 ( without post-COVID-19 syndrome)

Group II N=75 ( with post-COVID-19 syndrome)

The majority of those who had post-COVID-19 syndrome (85.3\%) had general manifestations (as malaise, fatigue, headache, and dizziness), $77.3 \%$ had musculoskeletal and joint complaints, $61.3 \%$ had mental and psychological problems (as depression, anxiety, memory, concentration and sleep disturbances, smell or taste disturbances), $58.7 \%$ had gastrointestinal manifestations (as dyspepsia), $44 \%$ had renal complaints, $41.3 \%$ had respiratory complaints (as dyspnea and cough), and 36.0\% had cardiovascular symptoms (as chest pain, palpitations, and tachycardia) (Figure 1). 


\section{Cureus}

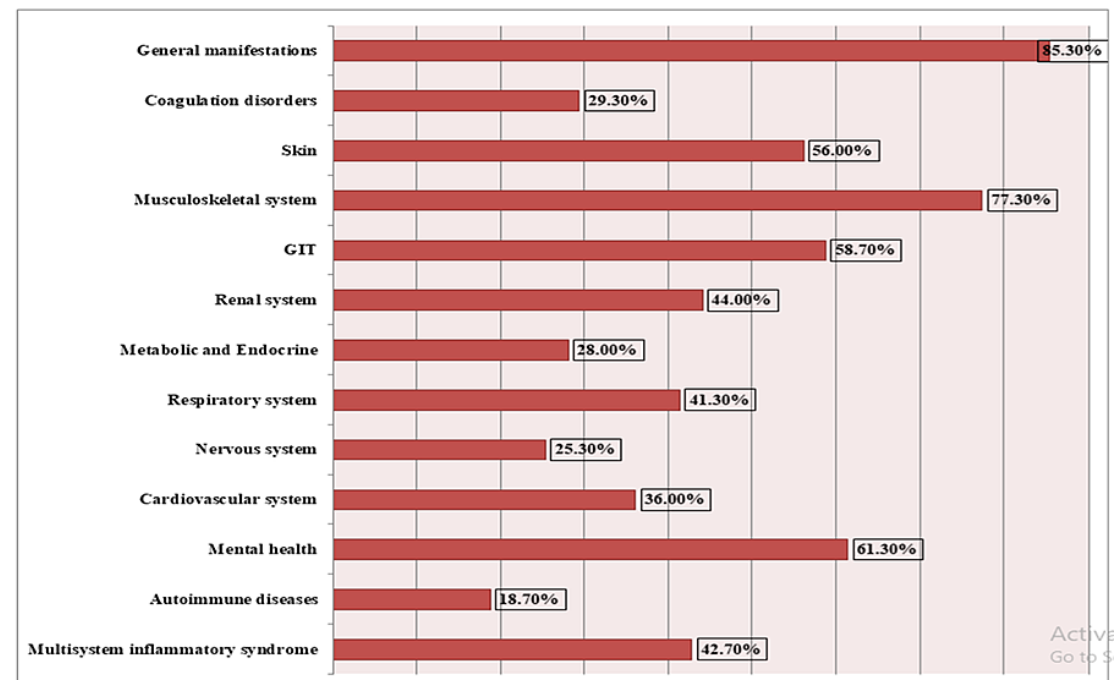

FIGURE 1: Clinical presentations of Group II studied participants (postCOVID-19)

GIT: gastrointestinal tract

Gender, age, smoking, BMI, associated co-morbid condition, number of previous COVID-19 attacks, the severity of illness, place of treatment, and complications of COVID-19 due to treatment or hospitalization were significantly correlated with the occurrence of the post-COVID-19 syndrome (Table 4).

\begin{tabular}{|c|c|c|}
\hline & $\mathbf{r}$ & Sig. \\
\hline Gender & -.87 & $0.000^{* *}$ \\
\hline Age & .73 & $0.030^{*}$ \\
\hline Smoking history & .79 & $0.001^{* \star}$ \\
\hline BMI & .68 & $0.002^{* \star}$ \\
\hline Associated morbid conditions & .59 & $0.014^{*}$ \\
\hline Number of attacks of previous COVID-19 infection & .47 & $0.023^{\star}$ \\
\hline Severity of illness & .51 & $0.000^{* \star}$ \\
\hline Place of treatment & .63 & $0.012^{*}$ \\
\hline COVID-19 Complications due to treatment or hospital admission & .58 & $0.033^{*}$ \\
\hline
\end{tabular}

\section{TABLE 4: Significant correlations with post-COVID-19 syndrome}

${ }^{*}$ Correlation is significant at 0.05 (two-tailed)

${ }^{* *}$ Correlation is significant at 0.01 (two-tailed)

\section{Discussion}

This research was designed to identify manifestations and predisposing factors for post-COVID-19 syndrome in Saudi Arabia. The participants were divided according to the presence of post-COVID-19 manifestations into two equal groups; each included 75 participants namely Group I without post-COVID-19 manifestations and Group II with post-COVID-19 manifestations.

The post-COVID-19 syndrome is a syndrome of persistent symptoms or development of sequelae beyond 3 or 4 weeks from the onset of acute symptoms of COVID-19 attack regardless of the severity of this attack [912]. The exact mechanism for the syndrome, in general, is still unknown. Yet, one recent study [9] Which 
investigated the mechanism of severe post-COVID-19 syndrome form of the multisystem inflammatory syndrome in children determined that viral particles remaining in the gut long after initial COVID-19 infection and could pass into the bloodstream [9]. Another research [15] claimed that the mechanism of its development may be direct viral toxicity; endothelial damage and microvascular injury; immune system impaired regulation and stimulation of a hyperinflammatory state; hypercoagulability with resultant in situ thrombosis and macrothrombosis; and maladaptation of the angiotensin-converting enzyme 2 (ACE2) pathway [15].

The current work concomitant with other researches demonstrated that fever, dyspnea, anosmia/ cacosmia, and loss of taste were the most frequently encountered clinical manifestations of COVID-19. [9,16-19] The severity of these symptoms varies according to the presence of underlying morbid conditions [16, 20]. The present work revealed that respiratory, hepatic, renal, and cardiovascular comorbidities were encountered among the great proportion of the studied participants; especially those having post-COVID-19 syndrome. Moreover, these co-morbid conditions may predispose to the development of post-COVID-19 syndrome $[15,21]$.

The present work revealed that the main manifestations encountered among those with the post-COVID-19 syndrome were general manifestations (as fatigue, and malaise), musculoskeletal (muscle and joint pain), mental health (depression, anxiety, sleep, memory and concentration disturbances), respiratory (cough and dyspnea) and cardiovascular (palpations, arrhythmias, and chest pain). The same findings were reported by a comprehensive review of current literature on post-COVID-19 syndrome done by Nalbandian A et al on April $2021[22]$.

Mental stress, in general, has been reported to impair immunity, therefore, increasing susceptibility for diseases [23]. Moreover, infection with COVID-19 will negatively affect a patient's life, sleep pattern, and mood. That will predispose him again to a vicious circle of depression, stress and anxiety, and impaired immunity [24-26]. These findings were in coherence with our study results which revealed that a great portion of the study participants with post-COVID-19 syndrome experienced headaches, mental complaints in form of anxiety, depression, and sleep disturbances during their last COVID-19 attack. Those symptoms would precipitate stressful conditions that lower immunity and therefore predisposed them to post-COVID19 syndrome [23-16].

Until now, there is no promising treatment option for COVID-19, and the drugs used have many toxic side effects [27]. This may explain our result of a high percentage of reported complications among post-COVID19 syndrome patients treated from their last COVID-19 attack at hospitals. Another explanation is that those cases were severe enough to develop complications on their own so that they need hospitalization or intensive care admission.

The present study demonstrates that almost all study participants without post-COVID-19 syndrome had more vaccination coverage whether partially (with only one dose) or fully vaccinated (with two doses). Effective vaccines are important to prevent and control epidemics of emerging viruses as SARS-CoV-2 $[28,29]$. Vaccination prevents severe forms and hospitalization due to COVID-19 infection including postCOVID-19 syndrome.

The present study proved that male gender, smoking, increase in age, high BMI, associated comorbidities, number, place of treatment, severity, and associated complications of COVID-19 attacks; all were correlated with the development of the post-COVID-19 syndrome. Nalbandian A et al discussed all those parameters and considered them also as predisposing factors for the development of post-COVID-19 syndrome [22].

\section{Conclusions}

The post-COVID-19 syndrome is a serious complication following COVID-19, where some manifestations persist or developed after 4 weeks of COVID-19 attack and after a negative polymerase chain reaction (PCR) test. In Saudi Arabia, as in other countries, it was found that it could be manifested by fatigue, malaise, myalgia, joint pain, depression, anxiety, sleep, memory and concentration disturbances, cough, dyspnea, palpations, arrhythmias, and chest pain. It may be predisposed by male gender, smoking, old age, high BMI, comorbidities, and past COVID-19 attack with regard to the number, place of treatment, and occurrence of complications.

\section{Additional Information \\ Disclosures}

Human subjects: Consent was obtained or waived by all participants in this study. Ibn Sina National College (ISNC) Research and Ethics Committee issued approval H-04-03062021. Ethical approval for the study was obtained from Ibn Sina National College (ISNC) Research and Ethics Committee (IEC Ref No: H04-03062021) in accordance with the Declaration of Helsinki for Human Studies.(14) The Participation in the study was voluntary and during the online questionnaire, the participants were all informed about the purpose of the study and their right to refuse participation. Ethical conduct was maintained during data 
collection and throughout the research process. . Animal subjects: All authors have confirmed that this study did not involve animal subjects or tissue. Conflicts of interest: In compliance with the ICMJE uniform disclosure form, all authors declare the following: Payment/services info: All authors have declared that no financial support was received from any organization for the submitted work. Financial relationships: All authors have declared that they have no financial relationships at present or within the previous three years with any organizations that might have an interest in the submitted work. Other relationships: All authors have declared that there are no other relationships or activities that could appear to have influenced the submitted work.

\section{References}

1. Basics of COVID-19. (2021). Accessed: 2 June 2021: https://www.cdc.gov/coronavirus/2019-ncov/yourhealth/about-covid-19/basics-covid-19.html.

2. Symptoms of COVID-19. (2021). Accessed: 2 June 2021: https://www.cdc.gov/coronavirus/2019ncov/symptoms-testing/symptoms.html.

3. Khan S, Siddique R, Bai Q, et al.: Coronaviruses disease 2019 (COVID-19): Causative agent, mental health concerns, and potential management options. J Infect Public Health. 2020, 13:1840-4. 10.1016/j.jiph.2020.07.010

4. Rayan RA: Seasonal variation and COVID-19 infection pattern: a gap from evidence to reality . Curr Opin Environ Sci Health. 2021, 20:100238. 10.1016/j.coesh.2021.100238

5. Coronavirus. (2021). Accessed: 2 June 2021: https://www.who.int/health-topics/coronavirus.

6. Alrazeeni D: Knowledge, attitude, and practice toward COVID-19 among paramedics in Saudi Arabia: implications for educational program. Mar. 2021, 8:71-7.

7. Green MS, Nitzan D, Schwartz N, Niv Y, Peer V: Sex differences in the case-fatality rates for COVID-19-A comparison of the age-related differences and consistency over seven countries. PLoS One. 2021, 16:e0250523. 10.1371/journal.pone.0250523

8. Kordzadeh-Kermani E, Khalili H, Karimzadeh I: Pathogenesis, clinical manifestations and complications of coronavirus disease 2019 (COVID-19). Future Microbiol. 2020, 15:1287-305. 10.2217/fmb-2020-0110

9. Yonker LM, Gilboa T, Ogata AF, et al.: Multisystem inflammatory syndrome in children is driven by zonulindependent loss of gut mucosal barrier. J Clin Invest. 2021, 131:10.1172/JCI149633

10. Datta SD, Talwar A, Lee JT: A proposed framework and timeline of the spectrum of disease due to SARSCoV-2 infection: illness beyond acute infection and public health implications. JAMA. 2020, 324:2251-2. 10.1001/jama.2020.22717

11. Greenhalgh T, Knight M, A'Court C, Buxton M, Husain L: Management of post-acute covid-19 in primary care. BMJ. 2020, 370:m3026. 10.1136/bmj.m3026

12. van Kampen JJ, van de Vijver DA, Fraaij PL, et al.: Duration and key determinants of infectious virus shedding in hospitalized patients with coronavirus disease-2019 (COVID-19). Nat Commun. 2021, 12:267. 10.1038/s41467-020-20568-4

13. Daniel WW, Cross CL: Biostatistics: A Foundation for Analysis in the Health Sciences . Wiley, Hoboken; 2018.

14. WMA Declaration of Helsinki - Ethical Principles for Medical Research Involving Human Subjects . (2008). Accessed: 9 October 2020: https://www.wma.net/policies-post/wma-declaration-of-helsinki-ethicalprinciples-for-medical-research-involving-human....

15. Gupta A, Madhavan MV, Sehgal K, et al.: Extrapulmonary manifestations of COVID-19. Nat Med. 2020, 26:1017-32. 10.1038/s41591-020-0968-3

16. Huang C, Wang Y, Li X, et al.: Clinical features of patients infected with 2019 novel coronavirus in Wuhan, China. Lancet. 2020, 395:497-506. 10.1016/S0140-6736(20)30183-5

17. Chan JF, Yuan S, Kok KH, et al.: A familial cluster of pneumonia associated with the 2019 novel coronavirus indicating person-to-person transmission: a study of a family cluster. Lancet. 2020, 395:514-23. 10.1016/S0140-6736(20)30154-9

18. Wu Z, McGoogan JM: Characteristics of and important lessons from the coronavirus disease 2019 (COVID19) outbreak in China: summary of a report of 72314 cases from the Chinese Center for Disease Control and Prevention. JAMA. 2020, 323:1239-42. 10.1001/jama.2020.2648

19. Cheng $\mathrm{Y}$, Cheng $\mathrm{G}$, Chui $\mathrm{CH}$, et al.: $\mathrm{ABO}$ blood group and susceptibility to severe acute respiratory syndrome . JAMA. 2005, 293:1450-1. 10.1001/jama.293.12.1450-c

20. Khan S, Siddique R, Shereen MA, et al.: Emergence of a novel coronavirus, severe acute respiratory syndrome coronavirus 2: biology and therapeutic options. J Clin Microbiol. 2020, 58: 10.1128/JCM.00187-20

21. Williamson EJ, Walker AJ, Bhaskaran K, et al.: Factors associated with COVID-19-related death using OpenSAFELY. Nature. 2020, 584:430-6. 10.1038/s41586-020-2521-4

22. Nalbandian A, Sehgal K, Gupta A, et al.: Post-acute COVID-19 syndrome. Nat Med. 2021, 27:601-15. 10.1038/s41591-021-01283-Z

23. Chiang JJ, Cole SW, Bower JE, Irwin MR, Taylor SE, Arevalo J, Fuligni AJ: Depressive symptoms and immune transcriptional profiles in late adolescents. Brain Behav Immun. 2019, 80:163-9. 10.1016/j.bbi.2019.03.004

24. Iwamoto A, Kawai M, Furuse M, Yasuo S: Effects of chronic jet lag on the central and peripheral circadian clocks in CBA/N mice. Chronobiol Int. 2014, 31:189-98. 10.3109/07420528.2013.837478

25. Walker WH 2nd, Walton JC, DeVries AC, Nelson RJ: Circadian rhythm disruption and mental health. Transl Psychiatry. 2020, 10:28. 10.1038/s41398-020-0694-0

26. Khan S, Nabi G, Yao L, et al.: Health risks associated with genetic alterations in internal clock system by external factors. Int J Biol Sci. 2018, 14:791-8. 10.7150/ijbs.23744

27. Gao J, Tian Z, Yang X: Breakthrough: chloroquine phosphate has shown apparent efficacy in treatment of COVID-19 associated pneumonia in clinical studies. Biosci Trends. 2020, 14:72-3. 10.5582/bst.2020.01047

28. Zumla A, Chan JF, Azhar EI, Hui DS, Yuen KY: Coronaviruses - drug discovery and therapeutic options. Nat Rev Drug Discov. 2016, 15:327-47. 10.1038/nrd.2015.37 


\section{Cureus}

29. Khan S, Siddique R, Ali A, Xue M, Nabi G: Novel coronavirus, poor quarantine, and the risk of pandemic . J Hosp Infect. 2020, 104:449-50. 10.1016/j.jhin.2020.02.002 